Tạp chí Khoa học và Công nghệ biển T12 (2012). Số 1. Tr 43 - 56

\title{
NGHIÊN CÚU CƠ SỞ THỨC ĂN TỬ NHIÊN PHỤC VỤ NGHỀ NUÔI HẢI SẢN Ở MộT SỐ KHU VỰC THUỘC QUẦ ĐẢO TRƯờnG SA
}

\author{
NGUYỄN MINH NIÊN, TRÀN KIM HẦNG \\ Viện Nghiên cứu Nuôi trồng Thủy sản II \\ NGUYẼ̃N TH!̣ PHƯONG THANH \\ Trường Trung học Thủy sản \\ NGÔ XUÂN QUẢNG \\ Viện Sinh học Nhiệt đới
}

\begin{abstract}
Tóm tắt: Nghiên cứu được thực hiện tại 5 đảo (Truờng Sa, Sinh Tồn, Thuyền Chài, Đá Đông và Đá Tây) thuộc Quần đảo Truờng Sa (QĐTS) tù 25/12/2007 đến 15/01/2008. Tổng số 114 mẫu thưc vật phù du (TVPD), động vật phù du (ĐVPD) và động vật đáy (ĐVĐ) được thu tại 22 trạm. Mẫu được cố định bằng formol 4\% và được phân tích tại phòng thí nghiệm Viện Nghiên cứu Nuôi trồng Thủy sản II và Viện Sinh học Nhiệt đới theo các phuoong pháp truyền thống. Kết quả ghi nhận 112 loài TVPD ở QĐTS với mật độ trung bình là $888.000 \mathrm{tb} / \mathrm{m}^{3}$, trong đó ngành tảo silic (Bacillariophyta) chiếm 76,79\%. ĐVPD có 81 loài với mật độ trung bình là $11.735 \mathrm{con} / \mathrm{m}^{3}$, trong đó giáp xác chân chèo (Copepoda) có thành phần loài và mật độ vuoọt xa các loài khác. ĐVĐ có 51 loài, trong đó các loài thuộc lớp chân đầu (Gastropoda) chiếm 52,94\%. Tuy nhiên, số luợng và sinh khối của ĐVĐ thấp, tuơng ứng là $20-260 \mathrm{con} / \mathrm{m}^{2}$ và $0,1982-1,2511 \mathrm{~g} / \mathrm{m}^{2}$. Các loài là nguồn thức ăn tự nhiên cho tôm, cá chiếm số lượng lớn. Các đảo Truờng Sa, Sinh Tồn và Thuyền Chài phù hợp cho nuôi hải sản.
\end{abstract}

\section{I. ĐẶT VẤN Đî̀}

Quần đảo Trường Sa (QĐTS) gồm khoảng 148 đảo nhỏ, đảo san hô và đảo chìm rải rác trên một diện tích gần $410,000 \mathrm{~km}^{2}$ ở giữa biển Đông có đường bờ biển $926 \mathrm{~km}$, có tọa độ $8^{\circ} 38^{\prime}$ vĩ độ Bắc và $111^{\circ} 55^{\prime}$ kinh độ Đông [19] thuộc chủ quyền của Nước Cộng Hòa Xã Hội Chủ Nghĩa Việt Nam. Do ở xa đất liền, thời tiết không thuận lợi vào nhiều tháng trong năm và việc đi lại khó khăn nên các nghiên cứu về cơ sở thức ăn tự nhiên tại QĐTS được thực hiện chưa nhiều. Từ 1979, trong Chương trình hợp tác Việt Xô (1979-1985) có thu thập tài liệu về sinh vật phù du (SVPD). Tháng 4/1996, khảo sát liên hợp Việt Nam Philippin (VN-RP JOMSRE-SCS-1996) có nội dung nghiên cứu SVPD phần phía Tây QĐTS [2]. Trong Chương trình biển Đông - Hải Đảo (1993-1997) "Điều tra tổng hợp 
nguồn lợi sinh vật biển QĐTS”, nghiên cứu về SVPD được phân tích, tổng hợp và đánh giá. Năm 2001-2003, "Đánh giá nguồn lợi sinh vật và hiện trạng môi trường vùng biển quần đảo Trường Sa" được Viện Nghiên cứu Hải sản thực hiện, trong đó có nội dung nghiên cứu về SVPD $[5,6]$. Các nghiên cứu tập trung chủ yếu về thành phần loài, mật độ và sinh khối SVPD. Nghiên cứu về ĐVĐ chưa nhiều. Ngoài ra còn có nghiên cứu về rong của Đàm Đức Tiến và Nguyễn Văn Tiến [10]. Tuy nhiên, cơ sở khoa học về thức ăn tự nhiên để phát triển nuôi các đối tượng hải sản chưa được đánh giá đầy đủ. Để góp phần bổ sung dẫn liệu về thức ăn tự nhiên theo thời gian, phục vụ phát triển nghề nuôi hải sản, bài báo trình bày kết quả nghiên cứu thức ăn tự nhiên tại một số đảo thuộc QĐTS cuối năm 2007 và đầu năm 2008.

\section{VẬT LIÊU VÀ PHƯƠNG PHÁP}

\section{Phạm vi và thời gian nghiên cứu}

Khu vực nghiên cứu là 5 đảo thuộc QĐTS. Mẫu TVPD, ĐVPD và ĐVĐ được thu tại 22 trạm từ 25/12/2007 đến 15/01/2008 (bảng 1).

Bảng 1: Số lượng các nhóm mẫu thu tại quần đảo Trường $\mathrm{Sa}$

\begin{tabular}{|c|c|c|c|c|}
\hline Địa điểm & Thực vật phù du & Động vật phù du & Động vật đáy & Tổng số \\
\hline Trường Sa & $5 \times 2=10$ mẫu & $5 \times 2=10$ mẫu & $2+0=2$ mẫu* & 22 mẫu \\
\hline Sinh Tồn & $4 \times 2=8$ mẫu & 4 × $2=8$ mẫu & $4 \times 2=8$ mẫu & 24 mẫu \\
\hline Đá Tây & $4 \times 2=8$ mẫu & 4 × $2=8$ mẫu & $3+2=5$ mẫu & 21 mẫu \\
\hline Đá Đông & 4 × $2=8$ mẫu & 4 × $2=8$ mẫu & $1+0=1$ mẫu* & 17 mẫu \\
\hline Thuyền Chài & $5 \times 2=10$ mẫu & $5 \times 2=10$ mẫu & $5 \times 2=10$ mẫu & 30 mẫu \\
\hline Tổng số & 44 mẫu & 44 mẫu & 26 mẫu & 114 mẫu \\
\hline
\end{tabular}

Ghi chú: * không thu được mẫu định lượng do nền đáy quá cứng

\section{Phương pháp thu mẫu}

- Thực vật phù du: Mẫu định tính được thu bằng lưới phiêu sinh (mắt lưới $25 \mu \mathrm{m}$ ) có diện tích miệng lưới $0,2 \mathrm{~m}^{2}$; Mẫu đinh lượng được thu trực tiếp bằng bình thu mẫu $1000 \mathrm{ml}$.

- Động vật phù du: Mẫu định tính được thu bằng lưới phiêu sinh có đường kính mắt lưới $25 \mu \mathrm{m}$; Mẫu định lượng được thu qua 60 lít nước, lọc qua lưới phiêu sinh.

- Động vật đáy: Mẫu định tính thu bằng cào đáy, kéo một đường dài $(5 \mathrm{~m})$; Mẫu định lượng thu bằng gàu Peterson có diện tích miệng gàu là $0,025 \mathrm{~m}^{2}$, thu 3 gàu ở mỗi 
trạm. Mẫu được rửa qua sàng có mắt lưới $0,5 \mathrm{~mm}$.

Toàn bộ mẫu được cố định bằng formol $4 \%$ tại hiện trường.

\section{Phương pháp phân tích}

- Thực vật phù du: Quan sát dưới kính hiển vi DMLP, DMIL và định danh dựa vào các tài liệu của Hoàng Quốc Trương [11], Shirota [16], Taylor [17] và Tomas [18]. Xác định mật độ tế bào bằng phương pháp đếm số lượng trong buồng đếm $0,1 \mathrm{ml}$.

- Động vật phù du: Quan sát dưới kính hiển vi DMLP, DMIL và định danh dựa vào các tài liệu của Shirota [16], Nguyễn Văn Khôi [7], Nguyễn Tiến Cảnh [3]. Xác định mật độ bằng phương pháp đếm số lượng trong buồng đếm $3 \mathrm{ml}$.

- Động vật đáy: Định loại bằng phương pháp so sánh hình thái dựa vào các tài liệu của Saunders [15], Hayward \& Ryland [14] và Fauvel [13]. Định lượng bằng phương pháp đếm số lượng và cân khối lượng.

Mẫu TVPD và ĐVPD được phân tích tại phòng thí nghiệm Viện Nghiên cứu Nuôi trồng Thủy sản II và mẫu ĐVĐ tại Viện Sinh học Nhiệt đới.

\section{KẾT QUẢ VÀ THẢO LUẬN}

\section{Thực vật phù du}

TVPD ở QĐTS khá đa đạng với 112 loài thuộc 3 ngành tảo, trong đó ngành tảo silic có 86 loài, chiếm 76,79\% tổng số loài (bảng 2 và hình 1). Các giống loài bắt gặp gồm các giống loài phân bố rộng như Coscinodiscus excentricus, Cyclotella sp., Biddulphia pulchela, Leptocylindrus dannicus, Asterionella nocata, Climacosphenia moniligera, Licmophora abbreviata, Cylindrotheca closterium. Ở các đảo Đá Tây, Đá Đông, Trường Sa và Thuyền Chài đã ghi nhận loài Pseudo-nitzschia pungens thuộc danh mục tảo gây hại nhưng có tần số bắt gặp rất thấp. Ở một số nước Châu Âu, khi mật độ loài này trên 400.000 tế bào $/ \mathrm{m}^{3}$, thủy vực bị cấm khai thác các loài thân mềm làm thực phẩm [9].

Ngành tảo giáp có 20 loài, chiếm 17,86\%. Trong đó, có 7 loài thuộc danh mục tảo gây hại là Ceratium furca, C. fusus, C. tripos, C. macroceros, Dictyocha fibula, Prorocentrum micans, Dinophysis hastata được ghi nhận với tần số bắt gặp rất thấp tại các đảo Đá Tây, Đá Đông, Trường Sa và Thuyền Chài. Ilangovan cho rằng có hiện tượng "nở hoa" khi mật độ các loài Ceratium tripos, Prorocentrum micans đạt trên $1.000 .000 \mathrm{tb} / \mathrm{m}^{3}$ [12]. Ngành tảo lam chỉ có 6 loài, chiếm $5,36 \%$ gồm chủ yếu là các loài tảo dạng sợi thuộc giống Oscillatoria và Lyngbya. Loài Trichodesmium thiebautii, là loài tảo "nở hoa" khi mật độ tăng cao, có ở các đảo Sinh Tồn và Đá Tây với tần số bắt gặp rất thấp. 
Bảng 2: Thành phần loài thực vật phù du tại quần đảo Trường $\mathrm{Sa}$

(Tháng 12/2007-01/2008)

\begin{tabular}{|c|c|c|c|}
\hline TT & Thành phần loài & $\mathbf{T T}$ & Thành phần loài \\
\hline & Bacillariophyta & 28 & Chaetoceros diversus Cleve \\
\hline 1 & Coscinodiscus excentricus Ehrenberg & 29 & Chaetoceros pelagicus Cleve \\
\hline 2 & $\begin{array}{l}\text { Thalassiosira leptopus (Grunow ex Van } \\
\text { Heurck) Hasle \& G. Fryxell }\end{array}$ & 30 & Chaetoceros teres Cleve \\
\hline 3 & Coscinodiscus rothii Pavilard & 31 & Chaetoceros sp. \\
\hline 4 & Coscinodiscus marginatus Ehrenberg & 32 & Planktoniella sol (Wallich) Schutt \\
\hline 5 & Coscinodiscus radiatus Ehrenberg & 33 & Biddulphia pulchella Gran \\
\hline 6 & $\begin{array}{l}\text { Azpeitia nodulifera (A.W.F. Schmidt) } \\
\text { G.A. Fryxell \& P.A. Sims }\end{array}$ & 34 & Biddulphia obtusa (Kützing) Ralfs \\
\hline 7 & Coscinodiscus subtilis Ehrenberg & 35 & Biddulphia recticulum (Ehrenberg) Boyer \\
\hline 8 & Coscinodiscus sp. & 36 & Hemiaulus sinensis Greville \\
\hline 9 & Ethmodiscus gazella (Gernisch) Hustedt & 37 & Isthmia nervosa Kutzing \\
\hline 10 & Cyclotella sp. & 38 & Asterionella notata Grunow \\
\hline 11 & $\begin{array}{l}\text { Hemidiscus hardmanianus (Greville) } \\
\text { Mann }\end{array}$ & 39 & $\begin{array}{l}\text { Asterionellopsis glacialis (F. Castracane) F.E. } \\
\text { Round }\end{array}$ \\
\hline 12 & $\begin{array}{l}\text { Guinardia flaccida } \\
\text { Peragallo }\end{array}$ & 40 & Climacosphenia moniligera Ehrenberg \\
\hline 13 & Dactyliosolen antarcticus Castracane & 41 & Licmophora abbreviata Agardh \\
\hline 14 & Leptocylindrus danicus Cleve & 42 & Grammatophora marina (Lyngbye) Kützing \\
\hline 15 & Rhizosolenia alata forma gracillima Cleve & 43 & Striatella unipunctata (Lyngbye) C. Agardh \\
\hline 16 & Rhizosolenia calcar-avis M. Schultze & 44 & Cocconeis scutellum Ehrenberg \\
\hline 17 & Rhizosolenia crassispina Schroder & 45 & Trachyneis aspera (Ehrenberg) Grunow \\
\hline 18 & Rhizosolenia delicatula Cleve & 46 & Diploneis bombus Ehrenberg \\
\hline 19 & Bacteriastrum varians Lauder & 47 & Diploneis crabro Ehrenberg \\
\hline 20 & Bacteriastrum hyalinum Lauder & 48 & Diploneis smithii (Brebisson) Cleve \\
\hline 21 & Bacteriastrum elongatum Cleve & 49 & Gyrosigma strigile (W.Smith) Cleve \\
\hline 22 & Chaetoceros distans Cleve & 50 & Pleurosigma elongatum W. Smith \\
\hline 23 & Chaetoceros peruvianus Brightwell & 51 & Pleurosigma affine Grunow \\
\hline 24 & Chaetoceros lauderi Grunow & 52 & Pleurosigma pelagicum Peragallo \\
\hline 25 & Chaetoceros indicum Karsten & 53 & Pleurosigma compectum Greville \\
\hline 26 & Chaetoceros crinitus Schutt & 54 & Navicula tuscula (Ehrenberg) Van Heurck \\
\hline 27 & $\begin{array}{l}\text { Chaetoceros lorenzianus var. forceps } \\
\text { A.F.Meunier }\end{array}$ & 55 & Navicula sp. \\
\hline 56 & Navicula cancellata Donkin & 86 & Campylodiscus undulatus Schmidt \\
\hline 57 & Navicula menbranace Cleve & & Cyanophyta \\
\hline
\end{tabular}




\begin{tabular}{|c|c|c|c|}
\hline $\mathbf{T T}$ & Thành phần loài & TT & Thành phần loài \\
\hline 58 & Navicula lyra Ehrenberg & 87 & Lyngbya martensiana Menegh. ex Gomont \\
\hline 59 & Navicula sp. & 88 & Phormidium limosum (Dillwyn) P.C. Silva \\
\hline 60 & Amphora quadrata Gregory & 89 & Oscillatoria lutea Agardh \\
\hline 61 & Amphora lineolata Ehrenberg & 90 & Oscillatoria spl \\
\hline 62 & $\begin{array}{l}\text { Amphiprora gigantea var. kerguelensis } \\
\text { Grunow }\end{array}$ & 91 & Oscillatoria sp2 \\
\hline 63 & Amphiprora alata (Ehrenberg) Kützing & 92 & Trichodesmium thiebautii \\
\hline 64 & Cerataulina bergonii Peragallo & & Dinophyta \\
\hline 65 & Synedra hennedyana Gregory & 93 & Ceratium furca (Ehrenberg) Claparéde \& Lachmann \\
\hline 66 & $\begin{array}{lll}\text { Synedra pulcherrima } & \text { Hantzsch ex } \\
\text { Rabhenhorst }\end{array}$ & 94 & $\begin{array}{l}\text { Ceratium fusus (Ehrenberg) var. shuttii } \\
\text { Lemmermann }\end{array}$ \\
\hline 67 & Synedra W. Smith & 95 & Ceratium tripos forma atlanticum Ostenfeld \\
\hline 68 & Synedra ulna (Nitzsch) Ehrenberg & 96 & Ceratium breve var. curvutum Jorgensen \\
\hline 69 & $\begin{array}{lccc}\text { Synedra gaillonii } & \text { var. } & \text { macilenta } \\
\text { (Grunow) H.Peragallo } & & \\
\end{array}$ & 97 & Ceratium macroceros (Ehrenberg) Cleve \\
\hline 70 & $\begin{array}{l}\text { Cylindrotheca closterium (Ehrenberg) } \\
\text { Lewin \& Reimann }\end{array}$ & 98 & Ceratium teres Kofoit \\
\hline 71 & Nitzschia reversa W. Smith & 99 & Ceratium obesum Pavillard \\
\hline 72 & Nitzschia sigma var. intercendens Grunow & 100 & Ceratium candelabrum (Ehrenberg) Stein \\
\hline 73 & Nitzschia lorenziana Grunow & 101 & Ceratium pulchellum Schroder \\
\hline 74 & Nitzschia lanceolata W. Smith & 102 & Dinophysis hastata Stein \\
\hline 75 & Bacillaria paxillifer (O.F. Müller) Hendey & 103 & Peridinium diabolus var. longipes (Karsten) \\
\hline 76 & $\begin{array}{l}\text { Pseudo-nitzschia pungens Grunow ex } \\
\text { Cleve }\end{array}$ & 104 & Protoperidinium pallidum Ostenfeld \\
\hline 77 & Nitzschia hungarica Grunow & 105 & Prorocentrum micans Ehrenberg \\
\hline 78 & Nitzschia sp. & 106 & Peridinium spl \\
\hline 79 & Surirella ovalis Brébisson & 107 & Peridinium sp2 \\
\hline 80 & Surirella fastuosa Ehrenberg & 108 & Dictyocha fibula Ehrenberg \\
\hline 81 & Asterolampra marylandica Ehrenberg & 109 & Gymnodinium sp. \\
\hline 82 & Podocystis spathulata (Shadbolt) Frenguelli & 110 & Gonyaulax sp. \\
\hline 83 & Rhabdonema arcuatum (Lyngbye) Kützing & 111 & Goniodoma sp. \\
\hline 84 & Flagiogramma sp. & 112 & Diplopsalis sp. \\
\hline 85 & Campylodiscus echeneis Grunow & & \\
\hline
\end{tabular}

Mật độ TVPD khá cao, trung bình đạt 888.000 tế bào $/ \mathrm{m}^{3}$ (bảng 3). Tảo silic có mật độ cao nhất, 470.000 tế bào $/ \mathrm{m}^{3}$, tảo lam cũng có mật độ khá cao với 411.000 tế bào $/ \mathrm{m}^{3}$ do có các quần thể dạng sợi Oscillatoria và thấp nhất là tảo giáp, 7.000 tế bào $/ \mathrm{m}^{3}$. Trong mẫu 
định lượng chỉ gặp loài Ceratium fusus ở đảo Trường Sa nhưng mật độ thấp (4.000 tế bào/m $\left.\mathrm{m}^{3}\right)$.

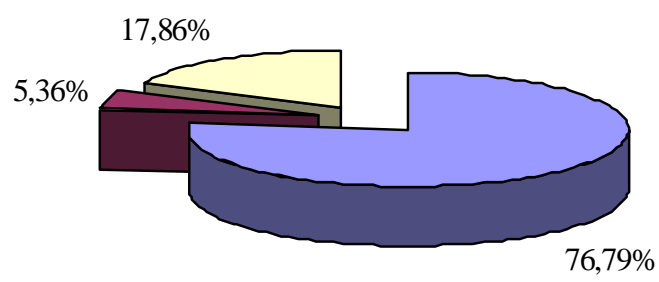

Bacillariophyta $\square$ Cyanophyta $\square$ Dinophyta

Hình 1: Cơ cấu thành phần loài thực vật phù du tại quần đảo Trường $\mathrm{Sa}$

Bảng 3: Mật độ thực vật phù du tại quần đảo Trường Sa (x1000 tế bào/m³)

\begin{tabular}{|c|c|c|c|c|c|c|c|}
\hline TT & Ngành tảo & Trường Sa & $\begin{array}{c}\text { Sinh } \\
\text { Tồn }\end{array}$ & $\begin{array}{c}\text { Thuyền } \\
\text { Chài }\end{array}$ & $\begin{array}{c}\text { Đá } \\
\text { Đông }\end{array}$ & Đá Tây & $\begin{array}{c}\text { Trung } \\
\text { bình }\end{array}$ \\
\hline 1 & Bacillariophyta & 820 & 1086 & 297 & 61 & 85 & 470 \\
\hline 2 & Cyanophyta & 603 & 531 & 700 & 0 & 219 & 411 \\
\hline 3 & Pyrrophyta & 4 & 7 & 10 & 13 & 2 & 7 \\
\hline \multicolumn{2}{r|}{ Tổng số } & 1427 & 1624 & 1007 & 74 & 306 & 888 \\
\hline
\end{tabular}

Nguyễn Tiến Cảnh và nnk [5] đã xác định 220 loài TVPD với mật độ 15.000 tb/m (giai đoạn 1993-1997) và 358 loài với mật độ 62.020 tb/m³ (giai đoạn 2001-2003) [6] là thức ăn của cá ở vùng biển QĐTS. Nguyễn Ngọc Lâm và Đoàn Như Hải [8] đã ghi nhận 264 loài TVPD, mật độ trung bình dưới 1.000 .000 tế bào $/ \mathrm{m}^{3}$ ở biển miền Trung vào mùa khô. So với các kết quả trên, sự sai khác về thành phần loài là do sự khác nhau về phạm vi, thời gian và số lượng mẫu. Tuy nhiên, thành phần loài và mật độ tại vùng nghiên cứu cao hơn so với vùng biển phía Tây Trường $\mathrm{Sa}$ của Đoàn Bộ và Nguyễn Dương Thạo [2], tương ứng là 99 loài và $171.899 \mathrm{tb} / \mathrm{m}^{3}$. Về cấu trúc, các kết quả nghiên cứu đều khá giống nhau, với ưu thế là các loài tảo Silíc.

\section{2. Động vật phù du}

Kết quả đã ghi nhận 81 loài ĐVPD thuộc 6 ngành. Ngành chân khớp (Arthropoda) có số loài nhiều nhất, 49 loài, chiếm $60,49 \%$. Trong đó, ưu thế là các loài thuộc lớp phụ chân chèo (Copepoda) với 41 loài. Tiếp đến là ngành động vật thân mềm (Mollusca) với bộ chân cánh và chân khác có 13 loài, chiếm 16,05\%. Ngành nguyên sinh động vật (Protozoa) có 12 loài, chiếm 14,81\%. Số còn lại chiếm tỷ lệ rất thấp (bảng 4 và hình 2). 
Bảng 4: Thành phần loài động vật phù du tại quần đảo Trường Sa

(Tháng 12/2007-01/2008)

\begin{tabular}{|c|c|c|c|}
\hline TT & Thành phần loài & TT & Thành phần loài \\
\hline & Ngành: Protozoa & 21 & Carinaria sp. \\
\hline 1 & Codonellopsis borealis Hada & 22 & Limacina inflata (d'Orbigny) \\
\hline 2 & $\begin{array}{l}\text { Codonellopsis ostenfeldi (Schmidt) Kofoid \& } \\
\text { Campbell }\end{array}$ & 23 & Limacina sp. \\
\hline 3 & Codonellopsis sp. & 24 & Limacina trochiformis (d'Orbigny) \\
\hline 4 & Ephidium sp. & 25 & Oxygurus keroudreni Lesueur \\
\hline 5 & Globigerina calida Blow & 26 & Peraclis sp. \\
\hline 6 & Globigerina falconensis Blow & & Bộ: Mytiloida \\
\hline 7 & Globigerina quinqueloba Natland & 27 & Mytilus edulis Linnaeus \\
\hline 8 & Globigerina sp. & 28 & Mytilus sp. \\
\hline 9 & Globigerina inflata d'Orbigny & & Ngành: Arthropoda \\
\hline 10 & Globorotalis pumilio & & Lớp phụ: Copepoda \\
\hline 11 & Textularia sp. & 29 & Acartia sp. \\
\hline \multirow[t]{3}{*}{12} & Tretomphalus bulloides d'Orbigny & 30 & Acrocalanus gracilis Giesbrecht \\
\hline & Ngành: Annelida & 31 & Acrocalanus longicornis Giesbrecht \\
\hline & Lớp: Polychaeta & 32 & Canthocalanus pauper (Giesbrecht) \\
\hline 13 & Eulalia viridis & 33 & Canthocamptus sp. \\
\hline 14 & Platynereis dumerilii (Audouin \& Milne Edwards) & 34 & Clausocalanus furcatus (Brady) \\
\hline \multirow[t]{3}{*}{15} & Âu trùng Polychaeta & 35 & Clytemnestra rostrata (Brady) \\
\hline & Ngành: Mollusca & 36 & Clytemnestra scutellata Dana \\
\hline & Bộ: Pteropoda \& Heteropoda & 37 & Copilia mirabilis Dana \\
\hline 16 & Agdina sp. & 38 & Copilia quadrata Dana \\
\hline 17 & Atlanta fusca Souleyet & 39 & Corycaeus crassiusculus Dana \\
\hline 18 & Atlanta inflata Souleyet & 40 & Corycaeus dahli Tanaka \\
\hline 19 & Atlanta souleyeti Smith & 41 & Corycaeus gibbulus Giesbrecht \\
\hline 20 & Atlanta sp. & 42 & Corycaeus sp. \\
\hline 41 & Corycaeus gibbulus Giesbrecht & 65 & Sapphirina angusta Dana \\
\hline 42 & Corycaeus sp. & 66 & Sapphirina scariata Giesbrecht \\
\hline 43 & Corycaeus pacificus F. Dahl & 67 & Sapphirina metallina Dana \\
\hline 44 & Corycaeus speciosus Dana & 68 & Sapphirina nigromaculata Claus \\
\hline 45 & Subeucalanus subcrassus (Giesbrecht) & 69 & Sapphirina sp. \\
\hline
\end{tabular}




\begin{tabular}{|c|c|c|c|}
\hline TT & Thành phần loài & TT & Thành phần loài \\
\hline 46 & Euchaeta longicornis Giesbrecht & & Bộ: Decapoda \\
\hline 47 & Euchaeta marina (Prestandrea) & 70 & Âu trùng tôm, cua dạng Zoae, Mysis \\
\hline 48 & Euterpina acutifrons Dana & 71 & Lucifer hanseni Nobili \\
\hline 49 & Labidocera euchaeta Giesbrecht & 72 & Lucifer intermedius Hansen \\
\hline 50 & Macrosetella gracilis Dana & 73 & Lucifer penicillifer Hansen \\
\hline 51 & Microsetella norvegica (Boeck) & & Bộ: Ostracoda \\
\hline 52 & Microsetella rosea Dana & 74 & Cypridina noctiluca (Ostracoda) \\
\hline 53 & Miracia efferata Dana & 75 & Cypridina sp. \\
\hline 54 & Nannocalanus minor (Claus) & & Lớp phụ: Malacostraca \\
\hline 55 & Neocalanus gracilis Dana & & Bộ: Amphipoda \\
\hline 56 & Oithona decipiens Farran & 76 & Hyperia latissima Bovallius \\
\hline 57 & Oithona fallax Farran & 77 & Hyperia schizogeneios Stebbing \\
\hline 58 & Oithona nana Giesbrecht & & Ngành: Chaetognatha \\
\hline 59 & Oithona similis Claus & 78 & Sagitta delicata Tokioka \\
\hline 60 & Oncaea media Giesbrecht & 79 & Sagitta enflata Grassi \\
\hline 61 & Oncaea mediterranea Claus & 80 & Sagitta minima Grassi \\
\hline 62 & Paracalanus nanus Sars & & Ngành: Echinodermata \\
\hline 63 & Paracalanus parvus Claus & 81 & Oikopleura rufescens (Tunicata) \\
\hline 64 & Paracyclopina nana Smirnov & & \\
\hline
\end{tabular}

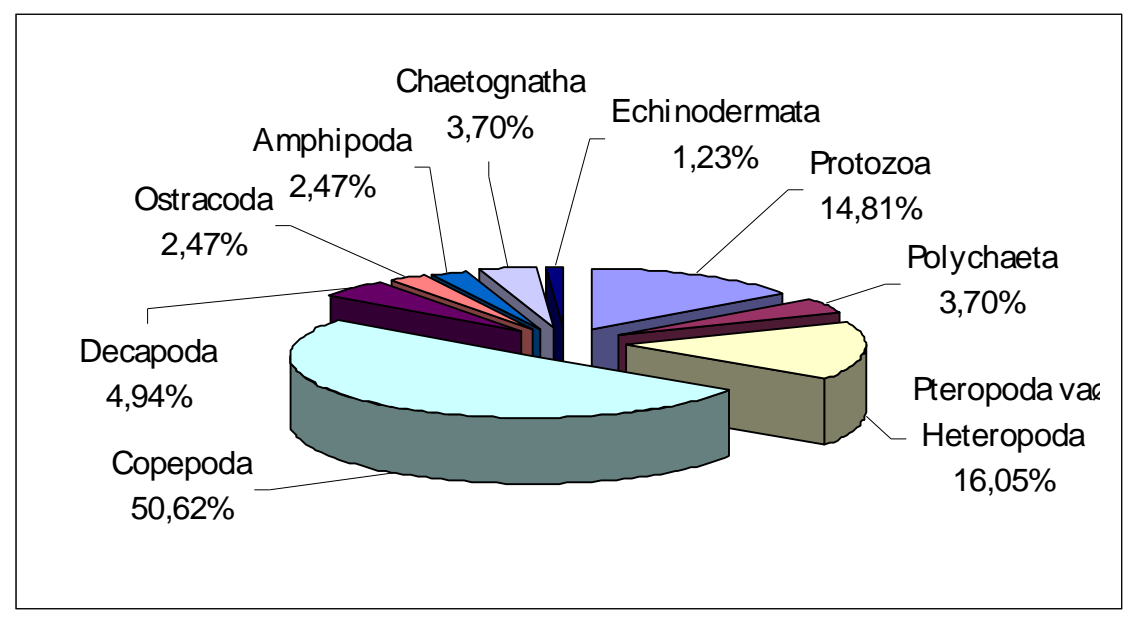

Hình 2: Cơ cấu thành phần loài động vật phù du tại quần đảo Trường Sa 
Mật độ ĐVPD khá cao, trung bình đạt $11.775 \mathrm{con} / \mathrm{m}^{3}$. Đảo Sinh Tồn có số lượng ĐVPD cao nhất $\left(20.000 \mathrm{con} / \mathrm{m}^{3}\right)$, kế đến là đảo Thuyền Chài $\left(17.800 \mathrm{con} / \mathrm{m}^{3}\right)$, đảo Trường $\mathrm{Sa}\left(11.000 \mathrm{con} / \mathrm{m}^{3}\right)$. Đảo Đá Đông có mật độ thấp nhất $\left(4.000 \mathrm{con} / \mathrm{m}^{3}\right)$ (bảng 5$)$.

Bảng 5: Mật độ động vật phù du tại quần đảo Trường $\mathrm{Sa}\left(\mathrm{con} / \mathrm{m}^{3}\right)$

\begin{tabular}{|l|r|r|r|r|r|r|}
\hline \multicolumn{1}{|c|}{ Vị trí thu mẫu } & \multicolumn{1}{c|}{ Trạm 1 } & Trạm 2 & Trạm 3 & Trạm 4 & \multicolumn{1}{c|}{ Trạm 5 } & Trung bình \\
\hline Trường Sa & 14500 & 12500 & 4500 & 12500 & 12000 & 11200 \\
\hline Sinh Tồn & 19500 & 18000 & 17500 & 25000 & - & 20000 \\
\hline Thuyền Chài & 39500 & 15500 & 8000 & 16500 & 9500 & 17800 \\
\hline Đá Đông & 5500 & 1500 & 6000 & 3000 & - & 4000 \\
\hline Đá Tây & 5000 & 4000 & 7000 & 7500 & - & 5875 \\
\hline Trung bình toàn vùng & & & & & & 11775 \\
\hline
\end{tabular}

Kết quả của Nguyễn Tiến Cảnh và nnk ghi nhận 223 loài ĐVPD ở QĐTS, trong đó có 20 loài thuộc 8 giống mới tìm thấy cho biển Việt Nam (giai đoạn 1993-1997) [5] và 358 loài (giai đoạn 2001-2003) [6] cao hơn nhiều so với kết quả nghiên cứu. Sự sai khác là do sự khác nhau về phạm vi, thời gian và số lượng mẫu nghiên cứu nhưng về cấu trúc thì khá giống nhau, lớp phụ chân chèo (Copepoda) chiếm đa số. Ngược lại, thành phần loài và số lượng ĐVPD cao hơn kết quả của Đoàn Bộ và Nguyễn Dương Thạo [2], tương ứng là 84 loài và $910 \mathrm{ct} / \mathrm{m}^{3}$ và gần giống với vườn Quốc gia Côn Đảo theo kết quả của Lê Xuân Ái [1]. Mật độ ĐVPD khá cao tại các đảo Sinh Tồn, Thuyền Chài và Trường Sa là một thuận lợi cho các loài hải sản ăn ĐVN.

\section{3. Động vật đáy}

Nghiên cứu đã xác định 51 loài ĐVĐ của 23 họ thuộc các nhóm thân mềm (Mollusca), giun nhiều tơ (Polychaeta), giáp xác (Crustacea), da gai (Echinodermata) và ấu trùng các loại. Trong đó, lớp chân đầu (Gastropoda) có 27 loài, chiếm 52,94\% tổng số loài (bảng 6 và hình 3). Tiếp theo là giáp xác Brachyura (Cua) có 8 loài, chiếm 15,69\%. Các nhóm khác chỉ có $1-3$ loài và 4 dạng ấu trùng thuộc nhóm thân mềm và cá con. Trong quần xã ĐVĐ, nhóm thân mềm, họ Cerithiidae có tới 11 loài và nhóm cua, họ Portunidae có 4 loài.

“'Số lượng ĐVĐ khá thấp, dao động từ 20 - $260 \mathrm{con} / \mathrm{m}^{2}$, cao nhất tại đảo Thuyền Chài và thấp nhất tại các đảo Đá Tây và Sinh Tồn. Chi phối mật độ là một số loài phát triển ưu thế như loài cua Matula planipes $\left(100 \mathrm{con} / \mathrm{m}^{2}\right)$, loài thân mềm Clypeomorus coralium $\left(80 \mathrm{con} / \mathrm{m}^{2}\right)$ và Clypeomorus moniliferus $\left(60 \mathrm{con} / \mathrm{m}^{2}\right)$. Sinh khối ĐVĐ tại các điểm khảo sát là rất thấp với khối lượng từ $0,0382 \mathrm{~g} / \mathrm{m}^{2}$ đến $2,55 \mathrm{~g} / \mathrm{m}^{2}$ (bảng 7). 
Bảng 6: Thành phần loài động vật đáy tại quần đảo Trường $\mathrm{Sa}$

(Tháng 12/2007-01/2008)

\begin{tabular}{|c|c|c|c|}
\hline TT & Thành phần loài & TT & Thành phần loài \\
\hline & Mollusca & 19 & Thais javanica (Philippi) \\
\hline & Bivalvia & & Rissoidae \\
\hline & Cardiidae & 20 & Rissoina reticula (Sowerby) \\
\hline \multirow[t]{2}{*}{1} & Trachycardium alternatum Sowerby & & Trochidae \\
\hline & Arcidae & 21 & Tectus fenestratus (Gmelin) \\
\hline \multirow[t]{2}{*}{2} & Barbatia foliata (Forsskål) & & Collumbellidae \\
\hline & Psammobiidae & 22 & Pyrene testudiaria (Link) \\
\hline \multirow[t]{3}{*}{3} & Gari amethystus (Wood) & 23 & Mitrella marquesa (Gaskoin) \\
\hline & Gastropoda & & Cypraeidae \\
\hline & Cerithiidae & 24 & Cypraea boivinii Kiener \\
\hline 4 & Rhinoclavis fasiata (Bruguiere) & & Fasciolariidae \\
\hline 5 & Clypeomorus petrosus (Wood) & 25 & Latirus gibbulus (Gmelin) \\
\hline 6 & Clypeomorus chemnitzianus (Pilbry) & 26 & Peristernia nassatula (Lamarck) \\
\hline 7 & Clypeomorus moniliferus (Kiener) & & Triphoridae \\
\hline 8 & $\begin{array}{l}\text { Clypeomorus batillariaeformis Habe \& } \\
\text { Kosuge }\end{array}$ & 27 & Inella pyramydalis (Adam\&Reeve) \\
\hline 9 & Clypeomorus coralium (Kiener) & & Haminoeidae \\
\hline 10 & Clypeomorus bifasciatus (Sowerby) & 28 & Atys cylindricus (Helbling) \\
\hline 11 & Clypeomorus sp. & & Olividae \\
\hline 12 & Cerithium tenellum Sowerby & 29 & Oliva oliva Linne \\
\hline 13 & Calyptraea extinctorium Lamarck & & Nassaridae \\
\hline \multirow[t]{2}{*}{14} & Batillaria multiformis (Lischke) & 30 & Nassarius pullus (Linnaeus) \\
\hline & Terebridae & & Polychaeta \\
\hline 15 & Terebra affinis Gray & & Glyceridae \\
\hline 16 & Xenoturris kingae Powell & 31 & Glycera chirori Izuka \\
\hline \multirow[t]{2}{*}{17} & Turridrupa cerithina (Anton) & & Opheliidae \\
\hline & Muricidae & 32 & Armandia intermedia Fauvel \\
\hline \multirow[t]{5}{*}{18} & Morula granulata Duclos & 33 & Travisia japonica Fujiwara \\
\hline & Crustacea & & Palemonidae \\
\hline & Decapoda & 43 & Conchodytes tridacnae Peters \\
\hline & Brachyura & & Anomura \\
\hline & Portunidae & & Paguridae \\
\hline
\end{tabular}




\begin{tabular}{|c|l|c|l|}
\hline TT & Thành phần loài & TT & Thành phần loài \\
\hline 34 & Neptunus argentatus Alcock & 44 & Clibanarius virescens (Krauss) \\
\hline 35 & Parathranites orientalis (Miers) & & Amphipoda \\
\hline 36 & Charybdis miles (de Haan) & & Ampeliscidae \\
\hline 37 & Charybdis bimaculata (Miers) & 45 & Ampelisca miharaensis Nagata \\
\hline & Portunidae & & Isopoda \\
\hline 38 & Pilumnus hirsutus Stimpson & 46 & Oniscus asellus Linnaeus \\
\hline & Callapidae & & Echinodermata \\
\hline 39 & Matula planipes (Fabriceus) & & Ophiolepididae \\
\hline 40 & Callappa sp. & 47 & Ophioplocus sp. \\
\hline & Majidae & & Âu trùng \\
\hline 41 & Camposcia retusa (Latreille) & 48 & Âu trùng Bivalvia \\
\hline & Macrura & 49 & Âu trùng Gastropoda \\
\hline & Aristaeidae & 50 & Cá con \\
\hline 42 & Aristeus viridis (Bate) & 51 & Âu trùng Crustacea \\
\hline
\end{tabular}

Bảng 7: Số lượng động vật đáy tại quần Đảo Trường Sa

\begin{tabular}{|c|c|c|c|c|}
\hline TT & Vị trí thu mẫu & Trạm & Số lượng (con/m²) & Sinh khối $\left(\mathrm{g} / \mathrm{m}^{2}\right)$ \\
\hline \multirow[t]{2}{*}{1} & \multirow[t]{2}{*}{ Đá Tây } & 1 & 40 & 1,948 \\
\hline & & 3 & 20 & 0,5542 \\
\hline \multirow[t]{5}{*}{2} & \multirow[t]{5}{*}{ Thuyền Chài } & 1 & 200 & 2,5542 \\
\hline & & 2 & 260 & 1,855 \\
\hline & & 3 & 100 & 0,132 \\
\hline & & 4 & 20 & 0,3212 \\
\hline & & 5 & 20 & 0,0742 \\
\hline \multirow[t]{4}{*}{3} & \multirow[t]{4}{*}{ Sinh Tồn } & 1 & 80 & 0,4982 \\
\hline & & 2 & 40 & 0,1292 \\
\hline & & 3 & 20 & 0,0382 \\
\hline & & 4 & 40 & 0,1272 \\
\hline
\end{tabular}




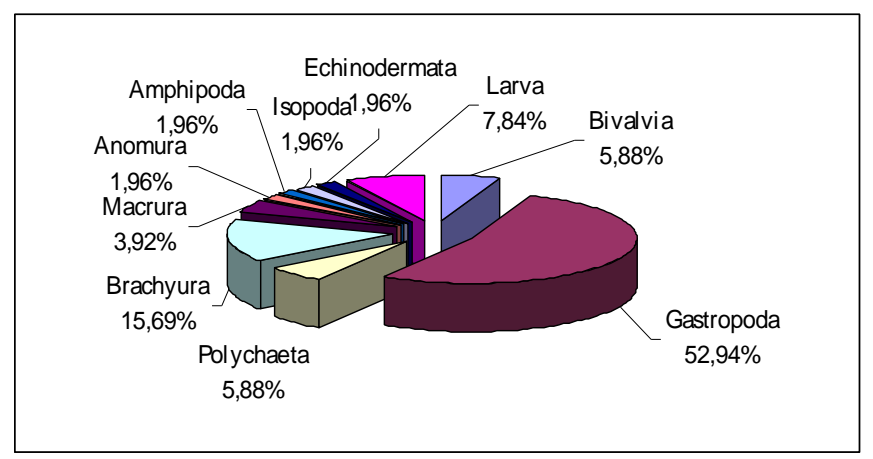

Hình 3: Cơ cấu thành phần loài động vật đáy tại quần đảo Trường $\mathrm{Sa}$

Theo kết quả của Nguyễn Tiến Cảnh (2005) có khoảng 143 -257 loài ĐVĐ tại các đảo chìm và 5 đảo nổi thuộc QĐTS (đảo Sinh tồn có 257 loài) [4] cao hơn nhiều so với kết quả nghiên cứu nhưng sinh vật lượng thì không cao hơn, chỉ từ $36-41 \mathrm{ct} / \mathrm{m}^{2}$. So với vườn Quốc gia Côn Đảo[1], thành phần loài ĐVĐ tại vùng nghiên cứu khá thấp có thể do nền đáy là cát và san hô, nghèo dinh dưỡng.

\section{KẾT LUẬN}

TVPD tại QĐTS khá đa dạng với 112 loài thuộc 3 ngành tảo, trong đó ngành tảo silic (Bacillariophyta) có 86 loài, chiếm $76,79 \%$ tổng số loài với mật độ trung bình là $888.000 \mathrm{tb} / \mathrm{m}^{3}$. Tại các đảo Sinh Tồn, Trường Sa và Thuyền Chài có mật độ cao nhưng tại các đảo Đá Đông và Đá Tây, TVPD kém phong phú. Sự khác biệt này có thể ảnh hưởng đến mắt xích của chuỗi thức ăn tự nhiên ở mỗi vùng.

ĐVPD đa dạng về thành phần loài ( 81 loài), trong đó giáp xác chân chèo (Copepoda) có 41 loài, chiếm 50,62\% với mật độ trung bình là $11775 \mathrm{con} / \mathrm{m}^{3}$. Mật độ ĐVPD khá cao tại các đảo Sinh Tồn, Thuyền Chài và Trường Sa là nguồn thức ăn tự nhiên tốt cho tôm, cá.

ĐVĐ có 51 loài. Trong đó, lớp chân đầu (Gastropoda) có 27 loài, chiếm 52,94\% tổng số loài nhưng số lượng và sinh khối khá thấp, chỉ từ $20-260 \mathrm{con} / \mathrm{m}^{2}$ và 0,1982 $1,2511 \mathrm{~g} / \mathrm{m}^{2}$ tương ứng. Đảo Thuyền Chài có số loài và số lượng nổi trội so với các đảo khác. Số lượng ĐVĐ thấp là điều kiện ít thuận lợi cho các loài nuôi ăn ĐVĐ.

\section{TÀI LIỆU THAM KHẢO}

1. Lê Xuân Ái, 1997. Bảo tồn đa dạng sinh học biển - Vườn Quốc gia Côn Đảo. Hội thảo về bảo tồn đa dạng sinh học ven biển, tr.23-30. 
2. Đoàn Bộ và Nguyễn Dương Thạo, 2001. Sinh vật phù du vùng biển phía Tây Trường Sa và mối quan hệ của chúng với các yếu tố môi trường. Tài nguyên và môi trường biển. Tập VIII. NXB. Khoa học và Kỹ thuật, Hà Nội, tr.229-237.

3. Nguyễn Tiến Cảnh, 1996. Sinh vật phù du và động vật đáy biển Việt Nam. Nguồn lợi thủy sản Việt Nam. NXB. Nông nghiệp, Hà Nội.

4. Nguyễn Tiến Cảnh, 2005. Đánh giá nguồn lợi sinh vật và hiện trạng môi trường vùng biển quần đảo Trường Sa. Tuyển tập các công trình nghiên cứu nghề cá biển, Tập III. NXB. Nông nghiệp, Hà Nội, tr.98-132.

5. Nguyễn Tiến Cảnh, Nguyễn Văn Khôi và Vũ Minh Hào, 2001. Sinh vật phù du vùng biển quần đảo Trường $\mathrm{Sa}$. Tuyển tập các công trình nghiên cứu nghề cá biển, Tập II. NXB. Nông nghiệp Hà Nội, tr.15-54.

6. Nguyễn Tiến Cảnh, Vũ Minh Hào và Nguyễn Hoàng Minh, 2005. Sinh vật phù $\mathrm{du}$ vùng biển quần đảo Trường Sa. Tuyển tập các công trình nghiên cứu nghề cá biển, Tập III. NXB. Nông nghiệp, Hà Nội, tr.13-68.

7. Nguyễn Văn Khôi, 1994. Lớp phụ chân chèo (Copepoda) vịnh Bắc bộ. NXB. Khoa học Kỹ thuật, Hà Nội, 198 tr.

8. Nguyễn Ngọc Lâm, Đoàn Như Hải, 1997. Phân bố thành phần loài và mật độ tế bào thực vật phù du vùng biển miền Trung. Tuyển tập báo cáo khoa học hội nghị sinh vật biển toàn quốc lần thứ I, tr.195-208.

9. Nguyễn Ngọc Lâm, Đoàn Như Hải và Hồ Văn Thệ, 1997. Định loại các loài thực vật phù du gây hại trong các thủy vực ven bờ, tỉnh Khánh Hòa. Phần 1. Báo cáo khoa học đề tài "Nghiên cứu sinh thái phát triển tảo gây hại và hiện tượng thủy triều đỏ liên quan đến các yếu tố môi trường”. Viện Hải dương học Nha Trang, 1997.

10. Đàm Đức Tiến và Nguyễn Văn Tiến, 2000. Rong kinh tế quần đảo Trường Sa. Tài nguyên và môi trường biển. Tập VIII. NXB. Khoa học và Kỹ thuật, Hà Nội, tr.235-246.

11. Hoàng Quốc Trương, 1962. Phiêu sinh vật trong vịnh Nha Trang. I. Khuê tảo, 213 tr.

12. Annamalai S., 1985. Noxious Dinoflagellates in Indian Waters. In: Toxic Dinoflagellates. Donald M. Anderson, Alan W. White, Daniel G. Baden Ed, 1985. New York - Amsterdam - Oxford, pp. 525-527.

13. Fauvel P. 1953. The fauna of India including Pakistan, Ceylon, Burma and Malaya, Annelida Polychaeta, Allahabad. 
14. Hayward P.J \& Ryland J.S., 1996. Handbook of Marine Fauna of North - West Europe, Oxford University Press, IBN 0-19-854054-X.

15. Saunders, G.D., 1979. Sppotter's guide to shells an introduction to seashells of the world. Unsborne Pblishing Limited, London, Great Britain, 65tr.

16. Shirota, A., 1966. The Plankton of South Vietnam. Freshwater and Marine Plankton. Overseas Technical Cooperation Agency, Japan, 416p.

17. Taylor, W.R., 1976. Marine algae of the eastern tropical and subtropical coasts of Americas. Second Edition. The University of Michigan Press. 870 pp.

18. Tomas, C.R., 1997. Identifying Marine Phytoplankton. New York: Academic Press, 858 p.

19. http://vi.wikipedia.org/wiki/Qu\%E1\%BA\%A7n_\%C4\%91\%E1\%BA\%A3o_Tr\%C6 \%B0\%E1\%BB\%9Dng Sa\#.C4.90.E1.BB.8Ba 1.C3.BD v.C3.A0 ph.C3.A1t tri.E1 .BB.83n kinh t.E1.BA.BF

\title{
NATURAL FOOD SOURCES SERVING AQUACULTURE IN SOME AREAS OF TRUONG SA ARCHIPELAGO
}

\section{NGUYEN MINH NIEN, NGUYEN THI PHUONG THANH, TRAN KIM HANG, NGO XUAN QUANG}

\begin{abstract}
Summary: The study was carried out in 5 islands (Truong Sa, Sinh Ton, Thuyen Chai, Da Dong and Da Tay) of Truong Sa archipelago from 25/12/2007 to 15/01/2008. A total of 114 samples of phytoplankton, zooplankton and zoobenthos were collected in 22 stations. Samples were fixed in the 4\% formaldehyde solution and were analyzed by traditional methods in the laboratories of the Research Institute for Aquaculture No.2 and the Institute of Tropical Biology. The result recorded 112 species of phytoplankton with an average density of $888.000 \mathrm{cells} / \mathrm{m}^{3}$ in study sites, of which Bacillariophyta species covered 76.79\%. There were 81 species of zooplankton with an average density of $11,735 \mathrm{inds} / \mathrm{m}^{3}$ in the study area. Among them the composition and density of Copepoda species exceeded others. There were 51 species of zoobenthos in Truong Sa area. Among them species of Gastropoda covered 52.94\%. The number and biomass of zoobenthos, however, were low with $20-260$ inds $/ \mathrm{m}^{2}$ and $0.1982-1.2511 \mathrm{~g} / \mathrm{m}^{2}$, respectively. Species, that serve as natural food sources for fish and shrimp covered high number. Marine culture is suitable in Truong Sa, Sinh Ton and Thuyen Chai islands.
\end{abstract}

Ngày nhận bài: 07 - 12 - 2010

Người nhận xét: PGS. TS. Nguyễn Ngọc Lâm 